\title{
Modulation of the Lexical-Semantic Network by Auditory Semantic Priming: An Event-Related Functional MRI Study
}

\author{
Sonja A. Kotz,* Stefano F. Cappa,† D. Y. von Cramon,* and A. D. Friederici* \\ *Max-Planck-Institute of Cognitive Neuroscience, 04393 Leipzig, Germany; and +Cognitive Neuroscience Center, \\ Universita Vita Salute San Raffaele, Milan, Italy
}

Received March 7, 2002

The current event-related fMRI study specifies the neuroanatomical correlates of semantic priming and differences in semantic relation types using an auditory primed lexical decision task (LDT). Word pairs consisted of different relation types, associations (key-chain), pure categorical relations (cow-dog), and unrelated words (table-window), as well as word-pseudoword (way-tinne) and pseudowordpseudoword (ahurn-döva) pairs. The factor lexical status, i.e., the processing of words compared to pseudowords, was associated with activation in the middle temporal gyri and the left striatum. The factor relatedness, i.e., the contrast between unrelated and related target words, was associated with increased activation of the left inferior frontal gyrus, the deep frontal operculum bilaterally, and the middle frontal gyri. A direct contrast between the two semantic relation types indicated that the processing of purely categorical compared to associative information recruits the right precuneus, the isthmus gyrus cinguli, and the cuneus, suggesting more effortful processing of the former information type. The present data show that the factors lexical status, semantic relatedness, and type of semantic relation in a primed LDT modulate the hemodynamic response in cerebral areas that subserve auditory word recognition and subsequent lexical-semantic processing. 02002 Elsevier Science (USA)

Key Words: auditory word processing; lexical decision; semantic priming; hemispheric lateralization.

\section{INTRODUCTION}

One important factor which has been shown to affect the pattern of brain activation during auditory single-word processing is the task associated with word recognition. Several functional brain imaging studies using positron emission tomography (PET) and functional magnetic resonance imaging ( $\mathrm{fMRI}$ ) have employed "passive" word presentation, i.e., a situation in which no overt response is required from participants. During this kind of task Wise et al. (1991) reported extensive bilateral activations of the primary and secondary auditory areas. These activations appear to be affected by acoustic intensity ( äncke et al., 1998) as well as by the rate of word presentation (Price \& al., 1992; Dhankhar et al., 1997). On the other hand, if a subject is required to perform a task requiring access to the meaning of auditory stimuli, the pattern of brain activation is more extensive. For example, if subjects are required to monitor a sequence of animal names for stimuli with predefined features (native to the United States and used by humans), an extensive network of cortical areas in the left hemisphere, including frontal, temporal, and parietal regions, becomes active (Binder et al., 1997). Similar results were observed when the subjects were monitoring for concrete or abstract words (Chee et al., 1999).

While the notion of an involvement of posterior temporoparietal regions during semantic processing was largely expected on the basis of lesion data (Hart and Gordon, 1990), the notion of an engagement of the frontal cortex during semantic tasks was unpredicted by aphasiological findings. Starting from the seminal observation that the left inferior frontal region was activated when subjects were engaged in processing the meaning of single words (generating a verb related to a noun, Petersen et al., 1988), the role of the frontal lobe in semantics has been the focus of intensive brain imaging investigation.

Before reviewing data about the neurological correlates of lexicosemantic processing, we will briefly discuss the relevant behavioral evidence on tasks that allow one to explore both word recognition and lexical-semantic processing.

One task which can be used for the investigation of the neural correlates of lexical-semantic processing is the lexical decision task, in its "pure" or "primed" version. In a pure lexical decision task subjects are required to differentiate words from pseudowords; responses to words compared to pseudowords are facilitated as the search within the mental lexicon is shorter for lexical entries than for items without a corresponding entry (e.g., Forster and Bednall, 1976; Allen et al., 1995; but see Seidenberg and McClelland, 1989; Plaut et al., 1996; for an alternative connectionist view). Semantic priming in primed lexical decision tasks is a behavioral (e.g., Neely, 1991) and an electrophysiological (e.g., Anderson and Holcomb, 1995) phenomenon which can be observed in auditory and visual word recognition tasks. The main characteristic of semantic priming is that a target word (i.e., dog) is recognized faster when it is preceded by a related prime word (i.e., cat) rather than by an unrelated prime word (i.e., table). 
Relevant processing dimensions that affect semantic priming are the stimulus-onset asymmetry (SOA) between a prime and a target word (e.g., de Groot, 1984; Neely, 1991), the proportion of related prime-target word pairs relative to all words and/or pseudowords in an experimental list (e.g., de Groot, 1984; Neely, 1991), and the type of semantic relation between a prime-target word pair (e.g., Tyler et al., 1995). While facilitated responses to related target words at brief SOAs are often considered to reflect automatic or unconscious access to lexical-semantic information (e.g., Collins and Loftus, 1975; McClelland and Rumelhart, 1985), access to related target words at longer SOAs seem to reflect controlled and conscious processes (e.g., Posner and Snyder, 1975; Neely, 1991). Furthermore, increasing the proportion of related prime-target word pairs enhances controlled and conscious processes during semantic priming (Neely, 1991).

Finally, it has been argued that priming as a function of different semantic relation types might reflect different levels of processing (e.g., Lupker, 1987; Shelton and Martin, 1992; Moss et al., 1995). For example, both pure categorical (cow-dog) and associative categorical (cat-dog) relations produce semantic priming effects, but associative priming appears to be stronger than categorical priming (e.g., Shelton and Martin, 1992; Moss et al., 1995; Kotz, 1998). Based on these results it has been proposed that categorical priming represents the activation of semantic representations at the conceptual level, while associative priming might reflect activation of associative relationships at the lexical form level, as associative connections between words form over time through co-occurrence of word forms in a language (e.g., Lupker, 1984; Moss et al., 1995).

Given the clear behavioral evidence that semantic priming affects lexical-semantic processing, the primed lexical decision task might be considered a useful candidate to elucidate the neural correlates of lexical-semantic processing and their modulation further. More precisely, the evidence derived from both the patient and the imaging literature on lexical decision and primed lexical decision allow the formulation of a working hypothesis on the possible role of the left inferolateral frontal area, in particular, and of temporalparietal areas of the language network in semantic priming.

Considering the neural underpinning of these processes, evidence from lesion studies implicates left inferolateral frontal areas in semantic priming. For example, Milberg et al. (1987) argued that Broca's aphasics, whose lesion typically involves the inferolateral frontal region, cannot automatically access lexical-semantic information, while Swinney et al. (1989) and Prather et al. (1991) postulated that the access of lexical-semantic information is intact, but slowed down. The latter results were extended by newer data reported by Blumstein and Milberg (2000), who claimed that a lexicalsemantic processing impairment in Broca's aphasics results from reduced activation of lexical entries in the lexical network. In contrast, both Tyler et al. (1995) and Hagoort et al. (1997) discussed on methodological grounds that Broca's aphasics can access lexical-semantic information in online tasks. However, Hagoort et al. (1997) described problems of controlled processing during semantic priming in Broca's aphasics. While patient data indicate that the left inferolat- eral frontal cortex is involved in lexical-semantic processing, its specific role remains a matter of debate. Overall, the lesion data are compatible with the hypothesis that damage to the left inferolateral frontal cortex does not result in a knowledge-based lexical-semantic deficit, but rather affects processing mechanisms that are involved in semantic priming.

Nevertheless, questions remain regarding how and to what extent aspects such as task type, task demands, and methodological changes such as varying SOAs, relatedness proportions, or different semantic relation types, all of which have been classically explored in primed lexical decision tasks (see Neely, 1991, for a review), affect the left inferolateral frontal cortex during lexical-semantic processing. Last, one immanent open question is which part of the left frontal cortex plays a "regulative" role in lexical-semantic processing. As there is very little description about the localization and extent of the lesions in the above-mentioned patient studies, part of the controversial results could have been the locus and size of the lesion within the left frontal cortex.

The evidence from imaging studies is also controversial. PET and fMRI studies with visual word presentation (e.g., Herbster et al ., 1997; Rumsey et al., 1997; Fiez and Petersen, 1998; Price, 1996a; Brunswick et al., 1999) report that the left inferior frontal gyrus (IFG; mainly BA 44/45) is activated in the lexical decision task, but attribute this effect to grapheme-to-phoneme conversion processes. Furthermore, two re cent imaging studies (Mummery et al., 1999; Rossell et al., 2001) used a visual primed lexical decision task to reveal regions involved in lexical-semantic processes. Both studies described bilateral activation of the inferolateral frontal areas during lexical decision. The activation, however, was not modulated as a function of semantic priming. Mummery et al. (1999) reported that relative to a letter detection task, lexical decision activated the anterior and inferior portions of the left temporal lobe and the inferior frontal gyrus bilaterally (BA 47) with a left-sided prevalence. Semantic priming was inferred from the presence of correlations between the proportion of related targets and the activation in four brain areas. Activity in the left anterior temporal lobe, the anterior cingulate cortex, the right superior parietal lobe, and the right premotor region decreased as a function of increasing the amount of related targets in the experimental set. The authors concluded that the left anterior temporal lobe is sensitive to lexical-semantic processing, while the left anterior cingulate and the right parietal lobe regulate attentional processes of semantic priming. Similarly, Rossell and colleagues (2001) found bilateral inferior frontal activation (BA 44/45) associated with lexical decision. They argued that semantic priming, when varied as a function of short and long SOAs, modulates the activity of the left anterior cingulate cortex (ACC). The authors confirmed this predication and reported activation of the left rostral ACC for short SOA semantic priming and the caudal ACC for long SOA semantic priming. In addition, activation of right-hemisphere areas (i.e., insula, superior temporal gyrus) were seen for both SOAs, while for long SOA priming, the bilateral middle temporal gyri, the putamen, the hippocampus, and the right supramarginal gyrus were activated as well. 
To summarize, the imaging studies that have used lexical decision and primed lexical decision tasks reveal that the activation of the inferior frontal region seems to occur only when lexical decision is in focus, independent of priming effects. However, while the activation of temporal lobe re gions during lexical-semantic processing seems to occur independent of task demands (e.g., Price et al., 1994, 1997; Rumsey et al., 1997; Mummery et al., 1996; Vandenberghe et al., 1996), the activation of the inferolateral frontal cortex appears to be more variable and to correlate with task demands. The latter point is particularly relevant as there is recent imaging evidence indicating that the inferior frontal cortex (i.e., BA 45/47) activation is dependent on the specific processing requirements of the semantic task, suggesting a strategic role in semantic processing (Fiez, 1997; ThompsonSchill et al. 1997; Mummery et al., 1999; Friederici et al., 2000b). On the other hand, some of the lesion data implicating the inferolateral frontal region in semantic priming have suggested an automatic role in semantic processing (e.g., Milberg et al., 1987). Given the processing dimensions (e.g., SOA, relatedness proportion, semantic relation types) that can influence semantic priming one would expect a modulation of the left inferolateral frontal area by semantic priming.

Another possible indication that the inferolateral frontal area may actually be involved in semantic priming comes from a different class of priming tasks, i.e., repetition priming. Buckner et al. (2000) have recently shown that activation of left frontal regions decreases as a function of item repetition in both the auditory and the visual modality. As response facilitation of repeated items and related items shows behavioral parallels, it is plausible to speculate that neuronal activation would also show similarities (i.e., decreased activation for repeated and related items compared to new or unrelated items in the left IFG). The authors proposed that this modulation of the left IFG might reflect processing stages of lexical/semantic search and access. Thus, evidence from repetition priming further supports the argument that the left inferolateral frontal area plays a role during semantic priming.

A major open question then remains about the reasons why the previous imaging studies on semantic priming failed to show a modulation of the inferolateral frontal region for semantic priming. In the first place, there are methodol ogi cal factors to be considered. Both reported visual semantic priming studies used a block design. In particular, Mummery and colleagues critically stated that the mode of operation (i.e., block design) might influence the role of the frontal lobe during a specific task. The block design condition might be expected to minimize the requirements for regulation of the operation mode, a function which has been attributed to the frontal lobe.

Second, modality-specific aspects could also play a role. As most of the discussed studies were conducted in the visual modality one conclusion is that the left inferolateral frontal area activation reflects grapheme-to-phoneme conversion during lexical decision.

In the present experiment we investigated the neural mechanisms associated with auditory word recognition and their modulation by semantic priming in a primed lexical decision task. In addition, we explored semantic priming as a function of semantic relation types (associative vs categorical). This allowed us to look at the effects of auditory lexical decision by contrasting the activation of words and pseudowords, semantic priming in general, and associative and categorical semantic relations. The main focus of the investigation was to clarify the respective contribution of the inferolateral frontal cortex and of temporoparietal areas in semantic priming.

The following predictions were made for the respective effects. The contrast of the pseudoword and word condition was expected to provide further evidence for the effect of lexical status in auditory processing. While this aspect has been extensively investigated in the visual modality (see, for example, Hagoort et al., 1999; Fiebach et al., 2002), relatively little attention has been devoted to auditory processing. The inferolateral frontal area has been consistently found to be more active in the case of pseudowords, but only with visual presentation. In the case of auditory presentation, the increase in brain activity associated with pseudoword processing has been suggested to affect the posterior temporoparietal areas (Newman and Twieg, 2001).

As summarized above, two critical aspects, methodology and modality, may be responsible for the lack of primingrelated modulation of the left inferolateral frontal area in the previous imaging experiments (Mummery et al., 1999; Rossell et al., 2001) that investigated semantic priming. With regard to modality, the current experiment chose to utilize the auditory-primed lexical decision task to investigate priming effects in a different modality. If activation of the left inferolateral frontal area results from increased processing demands for unrelated targets, and not from graphemeto-phoneme conversion, the activation should be evident in the auditory modality. Controlled processing conditions (i.e., short interstimulus interval (ISI) between prime and target words) should therefore induce facilitation of related targets reflected in a decrease of activation in the left inferolateral frontal area, while activation should be greater for unrelated targets, reflecting increased processing demands. Last, the facilitation of different semantic relations may induce differential activation of associative and categorical information (see Tyler et al., 1995). In particular, right-hemisphere engagement is expected for categorical information processing (e.g., Chiarello et al., 1992).

In terms of the methodology, an event-related design should reveal lexical effects as well as semantic priming effects with greater sensitivity. If trials from different conditions (i.e., related vs unrelated, words vs pseudowords) are presented in a pseudorandomized order, this allows for a direct contrast of critical experimental conditions and should avoid predictability and sequence effects.

\section{METHODS}

\section{Material}

The acoustic stimulus material was spoken by a trained female speaker. Word intonation was controlled by presenting critical words and pseudowords in a sentence to keep the contours across words and pseudowords comparable. Critical 


\section{TABLE 1}

Mean and Standard Deviation (in Parentheses) of Stimulus Parameters

\begin{tabular}{llll}
\hline & \multicolumn{1}{c}{$\begin{array}{c}\text { Related } \\
\text { targets }\end{array}$} & $\begin{array}{c}\text { Unrelated } \\
\text { targets }\end{array}$ & $\begin{array}{c}\text { Pseudoword } \\
\text { targets }\end{array}$ \\
\hline $\begin{array}{l}\text { Word duration (ms) } \\
\text { Word frequency per } \\
\text { million }\end{array}$ & $573(124)$ & $587(113)$ & $557(97)$ \\
$\begin{array}{l}\text { Strength of semantic } \\
\text { relatedness }\end{array}$ & $29.3(52)$ & $30.0(39)$ & \\
Similarity rating & $3.91_{\text {associative }}(0.52)$ & $1.90(0.36)$ & \\
& $\begin{array}{l}3.68_{\text {categorical }}(0.75) \\
3.66_{\text {associative }}(0.71)\end{array}$ & $1.20(0.20)$ & \\
& $3.38_{\text {categorical }}(0.65)$ & & \\
\hline
\end{tabular}

Note Number of syllables was controlled across all conditions: 1.80 syllables (range 1-4).

items were then cut out of the sentence, digitized, and edited with the COOL software (Syntrillium Software Corp.). During auditory word presentation, volume was controlled by the software gain controls and the manual configuration of the sound card. A total of five word-pair conditions were created: associatively related, Schlüssel-Kette (key-chain); categorically related, Kuh-Hund (cow-dog); unrelated, TischFenster (table-window); word-pseudoword: Haus-Tube (house-tube); and pseudoword-pseudoword, ahurn-döva. Categorical relationships were formed by exemplars of the same semantic category, coming from a range of categories. The factor animacy and frequency (Baayen et al., 1995) was controlled for target words across all critical conditions. Pseudowords were constructed by changing one phoneme from a real German word (diva-döva). Word associations were normed in a word generation test. Fifty-four subjects volunteered to generate up to three word associations for each of the 180 target words. Subjects were instructed to proceed as fast as possible without revising or rethinking their written word generation. The word association norms were generated to ensure that none of the generated primes were utilized as prime words in the categorical condition. Categorical prime words that were generated as associated prime words were excluded from the categorical word list. Furthermore, evaluated on a 5-point scale, the strength of the semantic relationship and the similarity of critical targets were evaluated in a norming study. Two experimental lists were created so that related target types were not repeated within one list. For specific information about the stimulus material see Table 1 .

To reduce scanner noise and to ensure the quality of the speech presentation, external ear defenders and perforated ear plugs that conducted the sound directly into the auditory passage were applied.

\section{Subjects}

Thirteen right-handed native speakers of German ( $7 \mathrm{fe}-$ male, mean age 23.5 years) listened to the auditory presentation of word and pseudoword pairs via headphones in the scanner. All subjects had normal hearing and no history of neurological, major medical, or psychiatric disorders. Before the scanning session written consent was obtained from all participating subjects according to the ethics committee regulations of the University of Leipzig, Germany.

\section{Psychophysical Procedure}

Each subject was presented with one of two lists of 320 stimulus pairs (160 word pairs, 40 associatively related, 40 categorically related, and 80 unrelated; 80 word-pseudoword pairs; and 80 pseudoword-pseudoword pairs) that were split into four runs of 80 pairs each. A trial started with a prime word followed by an interstimulus interval of $100 \mathrm{~ms}$ and the target word. The intertrial interval (ITI) was $8 \mathrm{~s}$. Given the thorough randomization of the trials, a short ITI in eventrelated fMRI studies has become acceptable, as hemodynamic responses can be obtained in rapidly spaced designs with randomly mixed trial types (Dale et al., 1997; Miezin et al., 2000; Pollmann et al., 2000). Participants were instructed to decide whether the target word was a German word by pressing a left response key for pseudowords and a right response key for words or vice versa; this was counterbalanced across subjects. Single trials were presented in a pseudorandomized order to balance sequence effects.

\section{Behavioral Data Acquisition}

Mean reaction times (RTs) and percentage error were calculated for each subject and across subjects for each of the critical conditions (word and pseudoword, unrelated and re lated, categorical and associative).

\section{Imaging Data Acquisition}

"Global shimming" for each individual subject was applied to adjust field homogeneity before MRI data acquisition. The alignment of structural and functional slices was based on the acquisition of scout echo sagittal scans that defined the anterior and posterior commissures on a midline sagittal section. Structural (T1) and functional (T2*) images (four gradient echo-planar sequences; TE $=40 \mathrm{~ms} ; \mathrm{TR}=2000 \mathrm{~ms}$ ) were acquired in eight horizontal slices along the bicommissural plane (AC-PC plane; thickness $5 \mathrm{~mm}$; gap $2 \mathrm{~mm}$ ) from a 3.0-T system (Bruker 30/100 Medspec). The in-plane resolution was $3 \times 3 \mathrm{~mm}$ (FOV $19.2 \mathrm{~cm}$ ). Due to the use of acoustic stimuli, only eight slices were acquired, as extensive pretesting confirmed that the volume of the EPI sequence would interfere with the differentiation of words and pseudowords. Thus, two slices were positioned below the AC-PC plane and six above, resulting in a field of view extending from -14 to +40 in the $z$ axis. The planes therefore covered all parts of the perisylvian cortex and the midfrontal gyrus according to the posed neuroanatomical hypotheses.

\section{Behavioral and Imaging Data Analyses}

Behavioral data were subjected to a statistical analysis of variance with thethree-way factor Relatedness (associatively related vs categorically related vs unrelated) for the RTs and percentage correct (Table 2). Where necessary follow-up analyses of more than two comparisons were Bonferroni adjusted. We report all $P$ values as $<0.01,<0.05$, or $>0.05$. 


\section{TABLE 2}

Mean Reaction Times in Milliseconds, Percentage Error, and Standard Deviation (in Parentheses) by Condition

\begin{tabular}{lcc}
\hline & Reaction times & Percentage error \\
\hline Words & $905(164)$ & $18.0(6.1)$ \\
Pseudowords & $983(168)$ & $24.1(3.4)$ \\
Associatively related targets & $839(185)$ & $3.0(7.8)$ \\
Categorically related targets & $869(198)$ & $7.7(10.3)$ \\
Unrelated targets & $962(188)$ & $9.6(16.2)$ \\
\hline
\end{tabular}

For the experimental run, the first four trials were excluded from the analyses to allow for stability in magnetization. Data processing was realized with the LIPSIA software (Lohmann et al., 2001). Functional data were reconstructed, and corresponding runs (four runs with 320 scans each, run duration $10 \mathrm{~min}$ ) were concatenated into a single run before the reconstruction of the MR signal. A temporal high-pass filter with a cut-off frequency of $1 / 80 \mathrm{~Hz}$ was used for baseline correction of the signal. The increased autocorrelation due to filtering was taken into account during statistical evaluation.

A rigid linear registration with 6 df (3 rotational, 3 translational) was performed to align the functional data slices onto a 3-D stereotactic coordinate reference system. The rotational and translational parameters were acquired on the basis of the MDEFT slices to achieve an optimal match between these slices and the individual 3-D reference data set, which was acquired before the first run for each subject. The MDEFT volume data set with 160 slices and 1-mm slice thickness was standardized to the Talairach stereotactic space (Talairach and Tournoux, 1988). The same rotational and translational parameters were normalized, i.e., transformed by linear scaling to a standard size. The resulting parameters were then used to transform the functional slices using trilinear interpolation to align the resulting functional slices with the stereotactic coordinate system.

The General Linear Model for serially autocorrelated observations was used for statistical evaluation based on a least-squares estimation (see also F riston, 1994; Worsley and Friston, 1995; Aguirre et al., 1997). First, for each participant, statistical parametric maps were generated and then averaged across subjects (Bosch, 2000). The design matrix was generated utilizing a synthetic hemodynamic response function (Friston et al., 1998) and a response delay of $6 \mathrm{~s}$. The model equation, including the observation data, the design matrix, and the error term, was convolved with a Gaussian kernel with a dispersion of $4 \mathrm{~s} F W H M$. The model includes an estimate of temporal autocorrelation that is used to estimate the effective degrees of freedom. The contrast between critical conditions was calculated using the t statistic. Subsequently, t values were transformed to $Z$ scores. As the individual functional data sets were all aligned to the same stereotactic reference space, a group analysis of $\mathrm{fMRI}$ data was performed by averaging individual $Z$ maps and multiplying each $Z$ value by the square root of $N$ ( $N$ is the number of participants; Bosch, 2000). To protect against false positive activations, only regions with a $Z$ score greater than $3.1(\mathrm{P}<$ 0.001 uncorrected) and with a volume greater than $180 \mathrm{~mm}^{3}$ (four connected voxels) were considered (Braver et al., 2001). Furthermore, error trials were rejected from all analyses.

\section{RESULTS}

\section{Behavioral Data}

Comparing the response times to words and pseudowords that reflect the factor lexical status revealed that participants responded faster to words than to pseudowords: $\mathrm{F}[1,12]=19.22, \mathrm{P}<0.01$. Looking at semantic priming, a main effect of Relatedness, $F[2,24]=27.11, P<0.01$, revealed that participants responded faster to related than to unrelated target words. Differences between categorical and associative target responses approached significance $(\mathrm{P}=$ 0.053). In general, subjects made the same amount of errors responding to words and pseudowords $(P>0.05)$. Thus, the high performance level which was on average above $92 \%$ correct showed that subjects were able to differentiate the auditory target items to a high degree in the scanner. Analyzing the percentage error data for semantic priming, there was a main effect of Relatedness, $F[2,24]=11.26, P<0.01$, indicating that participants made more errors responding to unrelated than to related targets. Participants made equal amounts of errors responding to associatively and categorically related targets: $P>0.05$. An overview of the results can be seen in Table 2.

\section{Imaging Data}

\section{Lexical Effect}

The pattern of brain activation associated with the lexical status for target words contrasted with target pseudowords is shown with its Talairach coordinates for the peak activity (Talairach and Tournoux, 1988) in Table 3 and graphically displayed in Figs. $1 \mathrm{~A}$ and $1 \mathrm{~B}$. The activations related to words involved the bilateral middle temporal gyrus (MTG), the left angular gyrus, and the left putamen and caudate subcortically. In contrast, pseudowords elicited more activation in the right deep frontal operculum, the right middle frontal gyrus (MFG), the bilateral inferior frontal sulcus (IFS), and the left anterior and middle superior temporal gyrus (STG).

\section{Semantic Priming Effect}

The semantic priming effect resulting from the contrast between targets preceded by an unrelated prime and targets preceded by a related prime is shown in Table 4 and Fig. 2. Unrelated target words showed differential activation in the left IFG, the bilateral deep frontal operculum, the bilateral MFG, the left IFS, and the bilateral planum temporale. In contrast, related target words showed enhanced activation in the left posterior MTG, the left postcentral sulcus/parietal operculum, and the left cuneus.

\section{Semantic Relation Effect}

The direct contrast between categorical and associative semantic relation types revealed differences in activation 
TABLE 3

Lexical Effect-Words versus Pseudowords

\begin{tabular}{|c|c|c|c|c|c|c|c|c|c|c|}
\hline \multirow[b]{2}{*}{ Location } & \multicolumn{5}{|c|}{ Left hemisphere } & \multicolumn{5}{|c|}{ Right hemisphere } \\
\hline & Z score & $x$ & $y$ & z & BA & Z score & $x$ & $y$ & z & BA \\
\hline \multicolumn{11}{|c|}{ Words > pseudowords } \\
\hline Anterior putamen & 4.41 & -23 & 13 & 1 & & - & - & - & - & \\
\hline Posterior putamen & 4.40 & -32 & 6 & 9 & & - & - & - & - & \\
\hline Caudate & 4.27 & -14 & 11 & 5 & & - & - & - & - & \\
\hline Middle temporal gyrus & 5.46 & -44 & -66 & 18 & 19 & 4.24 & 49 & -49 & 9 & 21 \\
\hline Middle temporal gyrus & 4.69 & -53 & -46 & 32 & 21 & - & - & - & - & \\
\hline Angular gyrus/tpTA & 5.92 & -36 & -62 & 32 & 40 & - & - & - & - & \\
\hline \multicolumn{11}{|c|}{ Pseudowords $>$ words } \\
\hline Inferior frontal sulcus & -3.30 & -34 & 4 & 29 & $6 / 8$ & -3.70 & 28 & 6 & 26 & $6 / 8$ \\
\hline Anterior superior temporal gyrus & -3.70 & -56 & 2 & 0 & 22 & - & - & - & - & \\
\hline Middle superior temporal gyrus & -4.80 & -56 & -22 & 9 & 22 & - & - & - & - & \\
\hline Deep frontal operculum & - & - & - & - & & -3.70 & 25 & 25 & 7 & \\
\hline Middle frontal gyrus & - & - & - & - & & -4.50 & 40 & 26 & 19 & $46 / 45$ \\
\hline
\end{tabular}

Note Tables 3, 4, and 5 list the results of direct comparisons between conditions. Z score indicates the magnitude of statistical significance. Localization is based on stereotactic coordinates (Talairach and Tournoux, 1988). These coordinates refer to the location of maximal activation indicated by the $Z$ score in a particular anatomical structure. Distances are relative to the intercommissural (AC-PC) line in the horizontal $(\mathrm{x})$, anterior-posterior $(\mathrm{y})$, and vertical $(\mathrm{z})$ direction. Thresholds for functional activation were set at $|\mathrm{Z}| \geq 3.1$. Only activation clusters exceeding a minimal volume size of $180 \mathrm{~mm}^{3}$ (>4 connected voxels) are listed.

only for the categorical type (see Table 5), in the right precuneus, right isthmus gyrus cinguli, and right cuneus. No areas were more active for the associative relation type.

\section{DISCUSSION}

The current event-related fMRI study set out to find the neuroanatomical correlates of auditory lexical decision and their modulation by semantic priming. Furthermore, we wanted to test whether the neural substrate of lexical-semantic processing is differentiated according to semantic relation types. It was predicted that, due to the lexicalsemantic processing nature of the task, a widespread activation of the left language cortex should be found. On the basis of previous imaging evidence, we postulated that semantic priming would modulate a network of areas, including the anterior temporal lobe (Mummery et al., 1999), but not the cingulate cortex (Mummery et al., 1999; Rossell et al., 2001), as we used a short ISI between prime and target words. A possible role for the left inferior frontal gyrus was predicted on the basis of lesions studies (see the introduction), as well as neuroimaging studies on lexical-semantic processing (e.g., Thompson-Schill et al., 1997). Furthermore, previous behavioral and clinical evidence (Chiarello et al., 1992; Hagoort et al., 1996; Kotz et al., 1999) indicated that the hemodynamic response to semantic relation types is likely to result in differential activation patterns, with a possible participation of the right hemisphere in the case of categorical priming. In the following discussion, we first address the behavioral results and then the imaging results, focusing in turn on the lexical effect, the semantic priming effect, and the semantic relation effect.

\section{Behavioral Effects}

With regard to the reaction time data, earlier findings were confirmed as lexical decision times were faster for words than for pseudowords (e.g., Holcomb and Neville, 1990; Neely, 1991). This has been attributed to exhaustive search in the mental lexicon (e.g., Forster, 1976). Alternatively, it has been claimed that pseudowords are inhibited by stronger lexical candidates (i.e., words), in particular when they are similar to words (Marslen-Wilson and Welsh, 1978; Elman and McClelland, 1984; Seidenberg and McClelland, 1989). Significant priming showed that participants were sensitive to the semantic relations between related prime-target pairs. Also, according to the predictions, semantic relation types differed in RTs. Subjects took longer to respond to a categorically related target word than to an associatively related target word (see also Neely, 1991; Moss et al., 1995). Thus, the present data do support the argument that the processing of associative and categorical semantic relations varies during lexical-semantic processing. A plausible explanation of this difference is that associative relations boost lexical-semantic processing (Moss et al., 1995).

\section{Lexical Effect}

During auditory lexical decision at the neural level, we observed the activation of a network of cerebral areas which are known to be engaged by lexical-semantic processing. As expected, these include frontal and temporal regions, as well as subcortical structures, with a left-sided prevalence.

Additionally, the current results provide clear evidence for stronger word than pseudoword activation in the left lateral temporal region and subcortical areas. On the other hand, for 


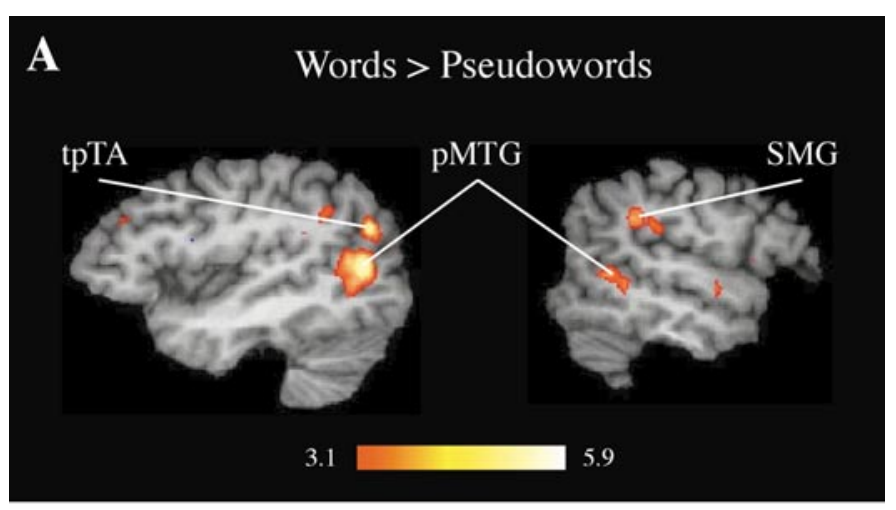

B
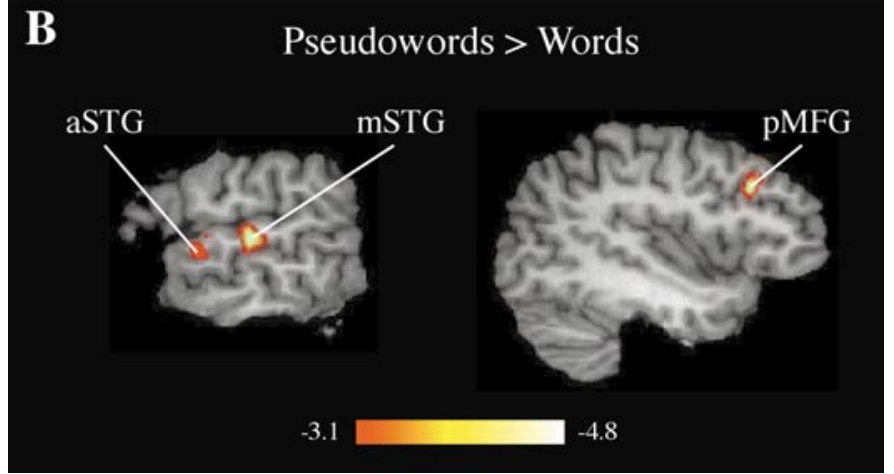

FIG. 1. Lexical effect-words versus pseudowords. Functional intersubject activation ( $N=13$ ) exceeding the significant threshold shown in left and right sagittal views. Displayed is the contrast between words and pseudowords across all experimental conditions. Functional activation was thresholded at $Z \geq 3.1$ for words and $Z \leq$ -3.1 for pseudowords. Slice selection coordinates (left) are for the direct contrast between words $(-43,-68,8)$ and pseudowords $(-55$, $-22,2$ ). Anatomical locations displayed in A and B and in Fig. 2 are abbreviated as follows: pMTG, posterior middle temporal gyrus; tpTA, temporoparietal transition area; SMG, supramarginal gyrus; aSTG, anterior superior temporal gyrus; mSTG, middle superior temporal gyrus; pMFG, posterior middle frontal gyrus; IFG, inferior frontal gyrus; HG, Heschl's gyrus.

pseudowords a clear bilateral frontolateral activation was found, which nevertheless did not include the inferior frontal gyrus.

Words elicited stronger left cortical (MTG and angular gyrus) and subcortical activation (striatum) than pseudowords. Activation of the left middle temporal gyrus confirms previous evidence that links phonological word form processing (Price et al., 1994; Hagoort et al., 1999), lexical-semantic processing (Pugh \& al., 1996), or semantic task demands (Friederici \& al., 2000b) to activation of this area. Furthermore, activation of the angular gyrus during lexical and semantic word processing confirms earlier reports (Petersen et al., 1988; Demonet et al., 1992; Kapur et al., 1994; Demb et al., 1995; Vandenberghe et al., 1996; Binder et al., 1997, 1999; Priceet al., 1997). Theactivation of the left striatum is in agreement with lesion data, supporting its role in lexical-semantic processing (Wallesch and Papagno, 1988). In addition, a number of imaging studies have reported activations in the left putamen during language processing, but have not discussed its functional significance (e.g., Klein \& al., 1994; Price et al.,1997).
The direct comparison used in the present experiment did not highlight activation in the inferior frontal gyrus associated with pseudoword processing, but rather in the IFS. Bilateral activation of this inferior frontal region for pseudoword processing in the auditory modality has been reported in PET studies and has been linked to explicit analyses of phonological units or sequences (Demonet \& al., 1992, 1994; Fiez et al., 1995; Zatorre et al., 1992, 1996). Similarly, Friederici et al. (2000a) showed in an auditory fMRI study that bilateral frontal areas are activated during the perception of pseudowords and pseudosentences. It was argued that deviant-to-normal speech input causes greater effort to discriminate sound segments during initial phonological analysis. Thus, the bilateral activation of the IFS for pseudowords is completely in line with previous evidence for auditory word processing.

Furthermore, for auditory pseudoword processing, we report activation of the left STG, an area that has previously been found for words (Binder et al., 1994, 1996; Friederici et al., 2000a). As pseudowords in the current experiment were very word-like, it is plausible that an attempt was made to lexicalize these pseudowords.

On a critical note, the current data as well as other findings (Newman and Twieg, 2001) are in contrast to results reported by Binder et al. (2000), who did not report activation differences between words and pseudowords. Several factors could have influenced this discrepancy. First, the present experiment utilized an event-related design rather than a blocked design. Second, words and pseudowords were directly contrasted rather than compared to another decision (i.e., letter decision) or a resting baseline. Therefore, methodological aspects could have enhanced differences between word and pseudoword activation patterns (see Mummery \& al., 1999, but also Binder et al., 2000). It is also possible that subjects in the primed lexical decision task were processing lexical and semantic information in parallel (see also Price et al., 1996a). Thus, differences between words and pseudowords might have been enhanced by the secondary

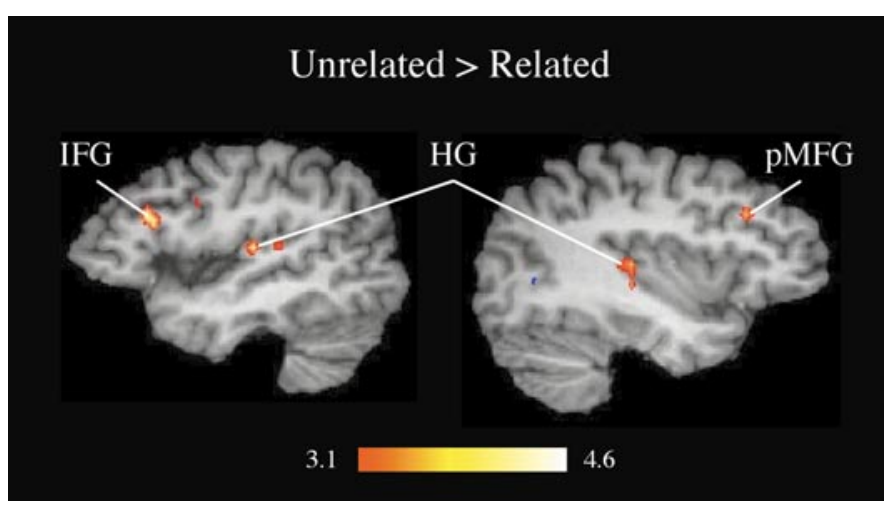

FIG. 2. Semantic priming effect-unrelated versus related targets. The significant activation patterns for unrelated (red) versus related (blue) targets are displayed in left and right sagittal views. Functional activation was thresholded at $Z \geq 3.1$ for unrelated targets and $Z \leq-3.1$ for related targets. The slice selection coordinates for the direct contrast between unrelated and related targets are left $(-45,-24,10)$ and right $(45,-24,10)$. 
TABLE 4

Semantic Priming Effect-Unrelated versus Related Targets

Left hemisphere

Location

Z score

$\mathrm{y}$

$z$

BA

\begin{tabular}{lllll}
\multicolumn{4}{c}{ Right hemisphere } \\
\hline Z score & $x$ & $y$ & $z$ & BA
\end{tabular}

Unrelated $>$ related

Inferior frontal gyrus

Deep frontal operculum

Middle frontal gyrus

Inferior frontal sulcus

Posterior HG/planum temporale

Anterior temporal operculum

Posterior middle temporal gyrus

Postcentral sulcus/parietal operculum

Cuneus

$\begin{array}{rrrr}4.06 & -47 & 22 & 14 \\ 4.51 & -32 & 24 & 11 \\ 3.68 & -38 & 18 & 2 \\ 4.01 & -35 & 2 & 2 \\ 3.96 & -41 & -25 & 1 \\ - & - & - & \end{array}$

Related $>$ unrelated

Note. Functional activation indicated separately for contrast between conditions. For explanations see Table 3 .

semantic priming task (see Demonet et al., 1992, 1994; Howard et al., 1992; Perani et al., 1996; Price et al., 1996b; Binder et al., 1999; for similar results when secondary tasks were involved).

\section{Semantic Priming Effect}

Regarding semantic priming, our results confirm the modulation of activation in the temporal lobe (e.g., Mummery et al., 1999) and in several frontal areas, including the left inferior frontal gyrus. This is in agreement with the hypothesis that activation in the left IFG varies as a function of semantic priming and does not merely reflect lexical-semantic information processing (see also Friederici et al., 2000b, for similar findings in receptive language tasks, but see also Mummery et al., 1999; Rossell et al., 2001).

The functional role of the left IFG during lexical-semantic processing is controversial. As summarized by Poldrack et al. (1999), it seems unlikely that the left IF G subserves semantic memory representations, as lesions in this area do not result in deficits of semantic knowledge. Rather, it has been suggested that activation of the left IFG might reflect "selection among competing alternatives regulated by semantic knowledge or recent experience" (see Thompsen-Schill et al., 1997). The stronger activation for unrelated than for related target words observed in the current study is in line with this view: the left IFG is activated, as selection for unrelated targets is more demanding than for related targets. This means that related targets are facilitated by the ongoing spreading activation of the prime, while unrelated targets necessitate greater effort in accessing a target word from semantic memory. Such an interpretation is further supported by the present behavioral data, as the responses to unrelated targets were significantly slower than the responses to related targets. A similar interpretation can also be found in the behavioral literature on the underlying processing mechanisms of semantic priming (e.g., Neely, 1991). In addition, the left IFG is also thought to involve different "executive" mechanisms such as retrieval, selection, and evaluation (see for an overview Poldrack et al., 1999, and for imaging studies Petersen et al., 1988, 1990; Demonet et al., 1992; Kapur et al., 1994; Buckner et al., 1995; Demb et al., 1995; Martin et al., 1995; Gabrieli et al., 1996; Wagner et al., 1997).

The modulation of the middle frontal gyrus is also in agreement with previous imaging studies of lexical-semantic processing (Petersen et al., 1988; Buckner et al., 1995; Grabowski et al., 1998; Binder et al., 1997) and can be interpreted in a similar fashion. In particular, Grabowski et al. (1998) have argued that activation of the MFG might correlate with the extent of mental search and response latency since they found stronger MFG activation and longer re-

\section{TABLE 5}

Semantic Relation Effect-Categorical versus Associatively Related Targets

\begin{tabular}{|c|c|c|c|c|c|c|c|c|c|c|}
\hline \multirow[b]{2}{*}{ Location } & \multicolumn{5}{|c|}{ Left hemisphere } & \multicolumn{5}{|c|}{ Right hemisphere } \\
\hline & Z score & $\mathrm{x}$ & $y$ & z & BA & Z score & $\mathrm{x}$ & $y$ & z & BA \\
\hline Precuneus & - & - & - & - & & 3.80 & 1 & -61 & 38 & 7 \\
\hline Isthmus gyrus cinguli & - & - & - & - & & 4.05 & 11 & -49 & 6 & $29 / 30$ \\
\hline Cuneus & - & - & - & - & & 4.22 & 13 & -64 & 12 & 17 \\
\hline
\end{tabular}

Note. Functional activation indicated separately for contrast between conditions. For explanations see Table 3. 
sponse latencies for specific word categories (names compared to tools or animals) in a category retrieval task. Such an argument could also be applied to the current results. Longer response latencies for unrelated target words than for related target words and enhanced activation of the bilateral MFG for unrelated target words could be the result of an extensive search in the semantic network It is noteworthy that the activation for unrelated target words was bilateral, which might be related to higher retrieval effort and reduced decision certainty (see Rugg and Wilding, 2000, for righthemisphere MFG activation). Again, this interpretation is in accordance with the longer reaction times and higher error rates for unrelated compared to related target words. A similar interpretation could be proposed for the left IFS activation.

Further notice needs to be given to the stronger bilateral activation of the deep frontal operculum for unrelated rather than for related target words. Similar activation has been reported during speech production, i.e., for articulatory planning (see Price, 2000), for word retrieval after hearing a repeated word (Buckner et al., 1995), or for naming after single-word reading (Moore and Price, 1999). As activation of the deep frontal operculum was also found during the perception of semantically empty, but syntactically structured, speech (Friederici et al., 2000a), it is possible that this brain area functionally serves as a co-occurring template match (i.e., prior experience) that allows one to evaluate semantic and structured relations between words or pseudowords.

Modulation of the bilateral planum temporale by unrelated targets is in accordance with the interpretation that the temporal lobe plays a crucial role in lexical-semantic processing (see Mummery et al., 1999), but more specifically during semantic priming (Mummery et al., 1999). It must be underlined, however, that the anterior part of the temporal lobe was not present in the field of view adopted for the present study. It is noteworthy that reduced and delayed semantic priming effects have been observed in patients with either left or right anterior temporal lesions (Kotz et al., 1999; Kotz and Friederici, 2002), further supporting the notion that semantic priming is modulated in the anterior temporal areas of both hemispheres.

The only areas which were more activated for related than for unrelated target words were the left posterior MTG, the left postcentral sulcus/parietal operculum, and the left cuneus. While activation of the left MTG has been reported for lexical retrieval of semantic (Friederici et al., 2000b) and categorical information (e.g., Grabowski et al., 1998), the left cuneus has been functionally linked to visual imagery (Fletcher, 1996). Thus, the two areas of activation might reflect specific retrieval processes, but also visual imagery as a function of concreteness for semantically related target words. One tentative and highly speculative interpretation could be to view this activation as part of a frontotemporal integrative semantic network, possibly involving visual imagery.

The lack of anterior cingulate activation in the present study stands in contrast to the two visual priming studies reported above. We attribute this difference to the fact that in the current study the ISI was short, and the proportion of related target words was low. Therefore, any modulation of the cingulate cortex which has been related to attentional demands during semantic priming was not expected.

\section{Semantic Relation Effect}

Finally, we turn to the differences in activation associated with semantic relation types. The only differences were observed in the case of categorically related targets which elicited activation of the right isthmus gyrus cinguli, the right precuneus, and the right cuneus. This implies that processing of categorical relations may be more effortful and also depends on right hemispheric areas. Supporting evidence comes from hemifield studies (Chiarello and Richards, 1992; Beeman et al., 1994) that utilized both RTs and fMRI and indicated a right-hemisphere advantage for pure coexemplar relations in comparison to associative relations. Such an interpretation also conforms with lesion studies that propose that the processing of coarse semantic information requires right-hemisphere involvement. Hagoort et al. (1996) and Swaab et al. (1998), for example, reported reduced coexemplar (categorical) priming in patients with broad right-hemisphere lesions. Extended right anterior temporal lobe lesions appear to result in both pure categorical and associative categorical priming deficits in comparison to pure associative priming (Kotz et al., 1999). These findings are in line with the hypothesis that neural processes underlying categorical re lations involve more processing effort than those underlying associative relations.

\section{CONCLUSION}

In summary, the present data indicate that the left inferolateral frontal region and bilateral temporal areas are crucial components of the neuronal network processing lexical-se mantic information modulated by semantic priming. In addition, there are differences in the pattern of brain activation according to semantic relation types (categorical or associative). The current data further specify the functional role of frontal, temporal, and subcortical areas of the lexical-semantic language network by revealing the effects of specific processing dimensions that modulate semantic priming in the auditory modality. Thus, the current $\mathrm{FMRI}$ data give evidence to the notion that the left inferolateral area plays a central role in lexical-semantic processing.

\section{ACKNOWLEDGMENTS}

The authors thank Christian Fiebach, Bertram Opitz, and Stefan Zysset for hel pful comments on the data analyses and Kerrie EIstonGuettler for comments on an earlier version of the paper.

\section{REFERENCES}

Aguirre, G., Zarahn, E., and D'Esposito, M. 1997. Empirical analyses of BOLD fMRI statistics. II. Spatially smooth data collected under null-hypothesis and experimental conditions. Neurol mage 5: 199212. 
Allen, P. A., Wallace, B., and Weber, T. A. 1995. Influence of case type, word frequency, and exposure duration on visual word recognition. J . Exp. Psychol. Hum. Percept. Perform. 21: 914-934.

Anderson, J. E., and Holcomb, J. P. 1995. Auditory and visual semantic priming using different stimulus onset asynchronies: An event-related brain potential study. Psychophysiology 32: 177190.

Baayen, R. H., Piepenbrock, R., and van Rijn, H. 1995. The CELEX Lexical Database(Release 2). Center for Lexical Information, MaxPlanck-Institute for Psycholinguistics, Nijmegen. [CD-ROM]

Beeman, M., Friedman, R. B., Grafman, J ., and Perez, E. 1994. Summation priming and coarse semantic coding in the right hemisphere. J . Cognit. Neurosci. 6: 26- 45.

Binder, J . R., Rao, S. M., Hammeke, T. A., Yetkin, Y. Z., J esmanowicz, A., Bandettini, P. A., Wong, E. C., Estkowski, L. D., Goldstein, M. D., Haughton, V. M., and Hyder, J. S. 1994. Functional magnetic resonance imaging of the human auditory cortex. Ann. Neurol. 35: 662-672.

Binder, J . R., Frost, J . A., Hammeke, T. A., Rao, S. M., and Cox, R. W. 1996. Function of the left planum temporale in auditory and linguistic processing. Brain 119: 1239-1247.

Binder, J . R., Frost, J . A., Hammeke, T. A., Cox, R. W., Rao, S. M., and Prieto, T. 1997. Human brain language areas identified by functional magnetic resonance imaging. J . Neurosci. 17: 353-362.

Binder, J . R., Frost, J . A., Hammeke, T. A., Bellgowan, P. S. F., Rao, S. M., and Cox, R. W. 1999. Conceptual processing during the conscious resting state: A functional MRI study. J . Cognit. Neurosci. 11: 80-93.

Binder, J. R., Frost J . A., Hammeke, T. A., Bellgowan, P. S. F., Springer, J . A., Kaufman, J . N., and Possing, E. T. 2000. Human temporal lobe activation by speech and non-speech sounds. Cereb. Cortex 10: 512-528.

Blumstein, S. E., and Milberg, W. P. 2000. In Language and the Brain (Y. Grodzinsky, L. Shapiro, and D. Swinney, Eds.), pp. 167-183. Foundation of Neuropsychology Series, Academic Press, San Diego.

Bosch, V. 2000. Statistical analysis of multi-subject fMRI data: The assessment of focal activations. J . Magn. Reson. Imaging 11: 6164.

Braver, T. S., Barch, D. M., Kelley, W. M., Buckner, R. L., Cohen, N. J ., Miezin, F. M., Snyder, A. Z., Ollinger, J. M., Akbudak, E., Conturo, T. E., and Petersen, S. E. 2001. Direct comparison of prefrontal cortex engaged by working and long-term memory tasks. Neurol mage 14: 48-59.

Brunswick, N., McCrory, E., Price, C. F., Frith, C. D., and Frith, U. 1999. Explicit and implicit processing of words and pseudowords by adult developmental dyslexics-A search for Wernicke's Wortschatz? Brain 122: 1901-1917.

Buckner, R. L., Raichle, M. E., and Petersen, S. E. 1995. Dissociation of human prefrontal cortical area across different speech production tasks and gender groups. J . Neurophysiol. 74: 2163-2173.

Buckner, R. L., Koutstaal, W., Schacter, D. L., and Rosen, B. R. 2000. Functional MRI evidence for the role of frontal and inferior temporal cortex in amodal components of priming. Brain 123: 620640.

Chee, M. W. L., O'Craven, K. M., Bergida, R., Rosen, B. R., and Savoy, R. L. 1999. Auditory and visual word processing studied with fMRI. Hum. Brain Mapp. 7: 15-28.

Chiarello, C., and Richards, L. 1992. Another look at categorical priming in cerebral hemispheres. Neuropsychology 30: 381-392.

Collins, A., and Loftus, E. 1975. A spreading activation theory of semantic processing. Psychol. Rev. 82: 407- 428.

Dale, A. M., and Buckner, R. L. 1997. Selective averaging of rapidly presented individual trials using fMRI. Hum. Brain Mapp. 5: 329-340.
De Groot, A. M. B. 1984. Primed lexical decision: Combined effects of the proportion of related prime-target pairs and the stimulus onset asynchrony of prime and target. Q. J . Exp. Psychol. 36: 253-280.

Demb, J . B., Desmond, J . E., Wagner, A. D., Vaidya, C. J ., Glover, G. H., and Gabrieli, J . D. E. 1995. Semantic encoding and retrieval in the left inferior prefrontal cortex: A functional MRI study of task difficulty and process specificity. J . Neurosci. 15: 5870-5878.

Demonet, J .-F., Chollet, F., Ramsay, S., Cardebat, D., Nespoulous, J .-L., Wise, R., Rascol, A., and Frackowiak, R. 1992. The anatomy of phonological and semantic processing in normal subjects. Brain 115: 1753-1768.

Demonet, J .-F., Price, C. J ., Wise, R., and Frackowiak, R. 1994. Differential activation of the right and left posterior sylvian regions by semantic and phonological tasks: A positron emission tomography study. Neurosci. Lett. 182: 25-28.

Dhankhar, A., Wexler, B. E., Fulbright, R. K., Halwes, T., Blamire, A. M., and Shulman, R. G. 1997. Functional magnetic resonance imaging assessment of the human brain auditory cortex response to increasing word presentation rates. J . Neurophysiol. 77: 476483.

Elman, J . L., and McClelland, J . L. 1984. In Speech and Language, Vol. 10, Speech Perception as a Cognitive Process: The Interactive Activation Model (N. Lass, Ed.). Academic Press, San Diego.

Fiebach, C. J ., Friederici, A. D., Müller, K., and von Cramon, D. Y. 2002. fMRI evidence for dual routes to the mental lexicon in visual word recognition. J . Cognit. Neurosci. 14: 11-23.

Fiez, J . A. 1997. Phonology, semantics, and the role of the left inferior prefrontal cortex. Hum. Brain Mapp. 5: 79-83.

Fiez, J . A., Raichle, M. E., Mietzin, F. M., Petersen, S. E., Tallal, P., and Katz, W. F. 1995. PET studies on auditory and phonological processing: Effects of stimulus characteristics and task demands. J. Cognit. Neurosci. 7: 357-375.

Fiez, J . A., and Petersen, S. E. 1998. Neuroimaging studies of word reading. Proc. Natl. Acad. Sci. USA 95: 914-921.

Fletcher, P. C., Shallice, T., Frith, C. D., Frackowiak, R., and Dolan, R. J . 1996. Brain activity during memory retrieval: The influence of imagery and semantic cueing. Brain 119: 1587-1596.

Forster, K. I. 1976. Accessing the mental lexicon. In New Approaches to Language Mechanisms (R. J . Wales and E. Walker, Eds.). North Holland, Amsterdam.

Forster, K. I., and Bednall, E. S. 1976. Terminating and exhaustive search in lexical access. Memory Cognit. 4: 53- 61.

Friederici, A. D., Meyer, M., and von Cramon, D. Y. 2000a. Auditory language processing: An event-related fMRI study on the processing of syntactic and lexical information. Brain Lang. 75: 289-300.

Friederici, A. D., Opitz, B., and von Cramon, D. Y. 2000b. Segregating semantic and syntactic aspects of processing in the human brain: An fMRI investigation of different word types. Cereb. Cortex 10: 698-705.

Friston, K. J . 1994. Statistical parametric maps in functional imaging: A general linear approach. Hum. Brain Mapp. 2: 189-210.

Friston, K. J ., Ashburner, J ., Frith, C. D., Poline, J . B., Heather, J . D., and Frackowiak, R. 1995. Spatial registration and normalization of images. Hum. Brain Mapp. 2: 165-189.

Friston, K. J ., Fletcher, P., J osephs, O., Holmes, A., Rugg, M. D., and Turner, R. 1998. Event-related fMRI: Characterizing differential responses. Neurol mage 7: 30-40.

Grabowski, T. J ., Damasio, H., and Damasio, A. R. 1998. Premotor and prefrontal category-related lexical retrieval. Neurol mage 7: 232-243.

Gabrieli, J . D. E., Desmond, J . E., Demb, J . B., and Wagner, A. D. 1996. Functional magnetic resonance imaging of semantic memory processes in the frontal lobes. Psychol. Sci. 7: 278-283. 
Hagoort, P. 1997. Semantic priming in Broca's aphasia at short SOA: No support for an automatic access deficit. Brain Lang. 56: 287300.

Hagoort, P., Brown, C., and Swaab, T. Y. 1996. Lexical-semantic event-related potential effects in patients with left hemisphere lesions and aphasia, and patients with right hemisphere lesions without aphasia. Brain 119: 627- 649.

Hagoort, P., Indefrey, P., Brown, C., Herzog, A., Steinmetz, H., and Seitz, R. J . 1999. The neural circuitry involved in the reading of German words and pseudowords: A PET study. J . Cognit. Neurosci. 11: 383-398.

Hart, J ., and Gordan, B. 1990. Delineation of single word semantic comprehension deficits in aphasia with anatomical correlation. Ann. Neurol. 27: 226-231.

Herbster, A. N., Mintun, M. A., Nebes, R. D., and Becker, J . T. 1997. Regional cerebral blood flow during word and nonword reading. Hum. Brain Mapp. 5: 84-92.

Holcomb, P. J ., and Neville, H. J . 1990. Auditory and visual semantic priming in lexical decision: A comparison using event-related brain potentials. Lang. Cognit. Proc. 5: 281-312.

Howard, D., Patterson, K., Wise, R., Brown, W. D., Friston, K. J ., Willer, C., and Frackowiak, R. 1992. The cortical localization of the lexicons. Brain 115: 1769-1782.

J äncke, L., Shah, N. J ., Posse, S., Grosse-Ryuken, M., and MüllerGärtner, H.-W. 1998. Intensity coding of auditory stimuli: An fMRI study. Neuropsychology 36: 875-883.

Kapur, S., Rose, R., Liddle, P. F., Zipursky, R. B., Brown, G. M., Stuss, D., Houle, S., and Tulving, E. 1994. The role of the left prefrontal cortex in verbal processing: Semantic processing or willed action? NeuroReport 5: 2193-2196.

Klein, D., Zatorre, R. J ., Milner, B., Meyer, E., and Evans, A. C. 1994. A cross-linguistic PET study of tone perception in Mandarin Chinese and English speakers. NeuroReport 5: 2295-2297.

Kotz, S. A. 1998. Comparing the auditory and visual sequential priming paradigm: An event-related potential study. J . Cognit. Neurosci. Suppl. 54.

Kotz, S. A., Friederici, A. D., and von Cramon, D. Y. 1999. Auditory word list priming in left and right temporal lobe lesions patients. Brain Lang. 69: 294-296.

Kotz, S. A., and Friederici, A. D. 2002. Electrophysiology of normal and pathological language processing. J. Neuroling., 10.1016/ 50911-6044(2)00008-8.

Lohmann, G., Müller, K., Bosch, V., Menzel, H., Hessler, S., Chen, L., Zysset, S., and von Cramon, D. Y. 2001. LIPSIA-A new software system for the evaluation of functional magnetic resonance images of the human brain. Comput. Med. Imaging Graph. 25: 449- 457.

Lupker, S. J. 1984. Semantic processing without associations: A second look. J . Verb. Learn. Verb. Behav. 23: 709-733.

Marslen-Wilson, W. D., and Welsh, A. 1978. Processing interactions during word recognition in continuous speech. Cognit. Psychol. 10: 29-63.

Martin, A., Haxby, J. V., Lalonde, F. M., Wiggs, C. L., and Ungerleider, L. G. 1995. Discrete cortical regions associated with knowledge of color and action. Science 270: 102-105.

McClelland, J . L., and Rumelhart, D. E. 1985. Distributed memory and representation of general and specific information. J . Exp. Psychol. Gen. 114: 159-188.

Mietzin, F. M., Maccotta, L., Ollinger, J . M., Petersen, S. E., and Buckner, R. L. 2000. Characterizing the hemodynamic response: Effects of presentation rate, sampling procedure, and the possibility of ordering brain activity based on relative timing. Neurol mage 11: 735-759.

Milberg, W., Blumstein, S., and Dworetzky, B. 1987. Processing of lexical ambiguities in aphasia. Brain Lang. 14: 371-385.
Moore, C. J ., and Price, C. J . 1999. Three distinct regions for word and picture naming in the ventral visual pathway. Neurol mage 10: 181-192.

Moss, H. E., Ostrin, R. K., Tyler, L. K., and Marslen-Wilson, W. D. 1995. Accessing different types of lexical semantic information: Evidence from priming. J . Exp. Psychol. Lang. Mem. Cogn. 21: 863- 883.

Mummery, C. J ., Patterson, K., Hodges, J . R., and Wise, R. J . S. 1996. Retrieving "tiger" as an animal name or a word beginning with T: Differences in brain activation. Proc. R. Soc. London B 263: 989-995.

Mummery, C. J ., Shallice, T., and Price, C. J . 1999. Dual-process model in semantic priming: A functional imaging perspective. Neurol mage 9: 516-525.

Neely, J . H. 1991. Semantic priming effects in visual word recognition: A selective review of current findings and theories. In Basic Processes in Reading-Visual Word Recognition (D. Besner and G. W. Humphreys, Eds.), pp. 264-337. Erlbaum, Hillsdale, NJ .

Newman, S. D., and Twieg, D. 2001. Differences in auditory processing of words and pseudowords: An fMRI study. Hum. Brain Mapp. 14: $39-47$.

Perani, D., Dehaene, S., Grassi, F., Cohen, L., Cappa, S. F., Dupoux, E., Fazio, F., and Mehler, J . 1996. Brain processing of native and foreign languages. NeuroReport 7: 2439-2444.

Petersen, S. E., Fox, P. T., Posner, M. I., Mintun, M., and Raichle, M. E. 1988. Positron emission tomographic studies of the cortical anatomy of single-words processing. Nature 331: 585-589.

Petersen, S. E., Fox, P. T., Snyder, A. Z., and Raichle, M. E. 1990. Activation of extrastriate and frontal cortical areas by visual words and word-like stimuli. Science 249: 1041-1044.

Plaut, D. C., McClelland, J . L., Seidenberg, M. S., and Patterson, K. 1996. Understanding normal and impaired word reading: Computational principles in quasi-regular domains. Psychol. Rev. 103: $56-113$.

Poldrack, R. A., Wagner, A. D., Prull, M. W., Desmond, J . E., Glover, G. H., and Gabrieli, J. D. E. 1999. Functional specialization for semantic and phonological processing in the left inferior prefrontal cortex. Neurol mage 10: 15-35.

Pollmann, S., Dove, A., von Cramon, D. Y., and Wiggins, C. J . 2000. Event-related $\mathrm{fMRI}$ : Comparison of conditions with varying BOLD overlap. Hum. Brain Mapp. 9: 26-37.

Posner, M. I., and Snyder, C. R. R. 1975. Attention and cognitive control. In Information Processing and Cognition: TheL oyola Symposium (R. L. Solso, Ed.). Erlbaum, Hillsdale, NJ .

Prather, P., Shapiro, L., Zurif, E., and Swinney, D. 1991. Real-time examinations of lexical processing in aphasics. J . Psycholing. Res. 20: $271-281$.

Price, C. J . 2000. The anatomy of language: Contributions from functional neuroimaging. J . Anat. 197: 335-359.

Price, C. J., Wise, R. J . S., Ramsay, S., Friston, K. J ., Howard, D., Patterson, K., and Frackowiak, R. 1992. Regional response within the human auditory cortex when listening to words. Neurosci. Lett. 146: $179-182$.

Price, C. J ., Wise, R. S. J ., Watson, J . D. G., Patterson, K., Howard, D., and Frackowiak, R. 1994. Brain activity during reading-The effect of exposure duration and task. Brain 117: 1255-1269.

Price, C. J ., Wise, R. S. J ., and Frackowiak, R. 1996a. Demonstrating the implicit processing of visually presented words and pseudowords. Cereb. Cortex 6: 62-70.

Price, C. J ., Wise, R. J . S., Warburton, E. A., Moore, C. J ., Howard, D., Patterson, K, Frackowiak R., and Friston, K. J . 1996b. Hearing and saying: The functional neuroanatomy of auditory word processing. Brain 119: 919-931. 
Price, C. J ., Moore, C. J ., Humphreys, G. W., and Wise, R. J . S. 1997. Segregating semantic from phonological processes during reading. J . Cognit. Neurosci. 9: 727-733.

Pugh, K. R., Shaywitz, B. A., Shaywith, S. E., Fulbright, R. K., Byrd, D., Skuldlarski, P., Shankweiler, D. P., Katz, L., Constable, R. T., Fletcher, J., Lacadie, C., Marchione, K., and Gore, J. C. 1996. Auditory selective attention: An $\mathrm{fMRI}$ investigation. Neurol mage 4: 159-173.

Rossell, S. L., Bullmore, E. T., Williams, S. C. R., Andrew, C., and David, A. S. 2001. Brain activation during automatic and controlled processing of semantic relations: A priming experiment using lexical decision. Neuropsychologia 39: 1167-1176.

Rugg, M. D., and Wilding, E. L. 2000. Retrieval processing and episodic memory. Trends Cognit. Sci. 4: 108-115.

Rumsey, J . M., Horwitz, B., Donohue, B. A., Nace, K., Maisog, J . M., and Andersen, P. 1997. Phonological and orthographic components of word recognition: A PET-rCBF study. Brain 120: 739-759.

Seidenberg, M. S., and McClelland, J . L. 1989. A distributed, developmental model of word recognition and naming. Psychol. Rev. 96: 523-568.

Shelton, J. R., and Martin, R. C. 1992. How semantic is automatic semantic priming? J . Exp. Psychol. Lang. Mem. Cogn. 18: 11911210.

Swaab, T. Y., Baynes, K., and Knight, R. T. 1998. Coarse semantic coding in the right hemisphere: An ERP study. In Fifth Annual Meeting of the Cognitive Neuroscience Society, San Francisco.

Swinney, D., Zurif, E., and Nicol, J . 1989. The effects of local brain damage on sentence processing: An examination of the neurological organization of a mental module. J . Cognit. Neurosci. 1: 25-37.

Talairach, J ., and Tournoux, P. 1988. Co-planar Stereotaxic Atlas of the Human Brain. Thieme, New York.
Thompson-Schill, S. L., D'E sposito, M., Aguirre, G. K., and Farah, M. J . 1997. Role of the left inferior prefrontal cortex in retrieval of semantic knowledge: A reevaluation. Proc. Natl. Acad. Sci. USA 94: 14792-14797.

Tyler, L. K., Ostrin, R. K., Cooke, M., and Moss, H. E. 1995. Automatic access of lexical information in Broca's aphasics: Against the automaticity hypothesis. Brain Lang. 48: 131-162.

Vandenberghe, R., Price, C. J., Wise, R. J. S., J osephs, O., and Frackowiak, R. 1996. Functional anatomy of a common semantic system for words and pictures. Nature 383: 254-256.

Wagner, A. D., Desmond, J. E., Demb, J. B., Glover, G. H., and Gabrieli, J . D. E. 1997. Semantic repetition priming for verbal and pictorial knowledge: A functional MRI study of left inferior-prefrontal cortex. J . Cognit. Neurosci. 9: 714-726.

Wallesch, C.-W. 1985. Two syndromes of aphasia occurring with ischemic lesions involving the left basal ganglia. Brain Lang. 25: 357-361.

Wallesch, C.-W., and Papagno, C. 1988. Subcortical aphasia. In Aphasia (F. C. Rose, R. Whurr, and M. A. Wyke, Eds.), pp. 256287. Whurr Pub., London.

Wise, R. J . S., Chollet, F., Hadar, E., Friston, K. J ., Hoffner, E., and Frackowiak, R. 1991. Distribution of cortical neural networks involved in word comprehension and word retrieval. Brain 14: 1803-1817.

Worsley, K., and Friston, K. J . 1995. Analysis of fMRI time-series revisited-Again. Neurol mage 2: 359-365.

Zatorre, R. J ., Evans, A. C., Meyer, E., and Gjedde, A. 1992. Lateralization of phonetic and pitch discrimination in speech processing. Science 256: 846- 849.

Zatorre, R. J ., Meyer, E., and Gjedde, A. 1996. PET studies of phonetic processing of speech: Review, replication and reanalysis. Cereb. Cortex 6: 21-30. 